Journal of Engineering Sciences, Assiut University, Vol. 37, No. 4, pp. 899-908, July 2009.

\title{
GAP FLOW BEHIND TWO PLATES HAVING ASYMMETRIC BEVELED TRAILING EDGE
}

\section{M. Mosallem , Zeinab A. Ahmed", and Abdullah Y. Al-Hossain}

\author{
* Assistant Prof., Faculty of Engineering, Minia University, Egypt \\ ** Ph. D., Consulting Engineer, Minia University, Minia, Egypt \\ *** Assistant Prof., Faculty of Science, Jazan University, Saudi Arabia
}

(Received March 18, 2009 Accepted April 11, 2009).

The effect of both gap size and Reynolds number variation on the flow between two plates having asymmetric beveled trailing edge placed sideby-side in a uniform stream have been investigated both numerically and experimentally. Two plates with gap ratios of $0.5,1.0$ and 1.5 and beveled trailing edge of angle $20^{\circ}$ have been tested. The effect of Reynolds number variation on the gap flow was examined for gap ratio $s / t=1.0$. The tested Reynolds number range was from $2.18 \times 10^{4}$ to $3.68 \times 10^{4}$. The results displayed that the gap size has a pronounced effect on the gap flow for gap ratios less than 1.5, where the wake behind the two plates shows an asymmetric development for gap ratios 0.5 and 1.0 and a symmetric development for gap ratio equal to 1.5. The results showed also that Reynolds number has a weak effect on the gap flow characteristics within the tested range of Reynolds number.

\section{NOMENCLATURE}

$\begin{array}{llll}C p & \text { Pressure coefficient, } & t & \text { Plate thickness [m] } \\ & C_{p}=\left(p_{s}-p_{\infty}\right) / 0.5 \rho U_{\infty}^{2} & s & \text { Plate spacing [m] } \\ p_{s} & \text { Surface pressure [Pa] } & U_{\infty} & \text { Freestream velocity [m] } \\ p_{\infty} & \text { Freestream static pressure [Pa] } & x & \begin{array}{l}\text { Distance from the leading edge } \\ \text { of the plates [m] }\end{array} \\ \operatorname{Re}_{t} & \text { Reynolds number based on } & \rho & \left.\text { Density [kg/m }{ }^{3}\right] \\ & \text { plate thickness, } & \mu & \left.\text { Dynamic viscosity [N.s } / \mathrm{m}^{2}\right] \\ & \operatorname{Re}_{t}=\rho U_{\infty} t / \mu & & \end{array}$

\section{INTRODUCTION}

The gap flow behind two side by side bluff bodies is present in many engineering applications such as flow between turbine blades, flat vanes placed in ducts to either straighten or aid in turning the flow, heat exchanger tubes, and other related structures and aerodynamic forces of neighboring high-rise buildings.

Wakes behind two bluff bodies interfere in a complex manner, depending on the spacing between the bodies. Flow behind two circular cylinders placed side-by-side in a uniform flow has been extensively investigated ([1]-[7]). Also the flow behind two 
square cylinders has been studied by Mosallem [8] and Agrawal et al. [9]. A number of reports in the literature have addressed the gap flow behind two plate arrays (10] [12]). Guillaume and LaRue [13] reported that the wakes of closely spaced bluff bodies may interact in several different patterns. They defined terms that describe three types of wake interactions as follows: 1- A quasi-stable behavior of the wake downstream of a plate array in which different base pressure coefficient $C_{p}$ values exist behind each plate. The $C p_{b}$ values do not vary with time. 2- Spontaneous flopping; a behavior observed downstream a plate array where the average value of $C_{p_{b}}$ is observed to alternate over time between relatively high and low values. 3- Forced flopping; a behavior observed downstream the plates in which initially stable wakes exhibit flopping as a result of a large, one time perturbation.

Recently, Mosallem [14] investigated the flow behind two plates having asymmetric beveled trailing edge placed side-by-side in a uniform stream for spacing (or gap) ratio of 1.0 and beveled trailing edge of angle $20^{\circ}$ at Reynolds numbers equal to $3.97 \times 10^{4}$. Both the numerical simulation results and the photographs obtained from the flow visualization displayed that the flow separates on one plate beveled trailing edge surface. The vortex formation and shedding from this plate led to deflecting the flow toward the other plate and consequently the wake behind the plates shows an asymmetric development.

The present investigation is a continuation of the work of Mosallem [14], where it aims to investigate the effect of both gap size and Reynolds number variation on the flow behind two-plates having beveled trailing edge of angle $20^{\circ}$ and arranged side-by-side to the approaching flow. Three gap ratios (plate spacing, $s$ to plate thickness, $t)$ were tested $(s / t=0.5,1.0$ and 1.5).

\section{COMPUTATIONAL DETAILS}

The flow is assumed to be turbulent and the Renormalized Group (RNG $k-\varepsilon$ ) turbulence model was used. Two dimensional incompressible steady flow computations were carried out to investigate the general features of the flow field. The computational domain is shown in Fig. 1. The flow is described in a Cartesian coordinate system, in which the $x$-axis is aligned with inlet flow direction. Fixed two-dimensional bluntfaced two-flat plates with a thickness $t$ and having asymmetric beveled trailing edge of angle $\theta=20^{\circ}$ were placed side-by-side in a uniform stream and were exposed to a constant free stream velocity. Water, with constant fluid properties is flowing. Numerical simulations are performed for gap ratios, $s / t$ of $0.5,1.0$ and 1.5 at Reynolds number, $\operatorname{Re}_{t}=3.97 \times 10^{4}$ based on plate thickness, $t$ and freestream velocity, $U_{\infty}$.

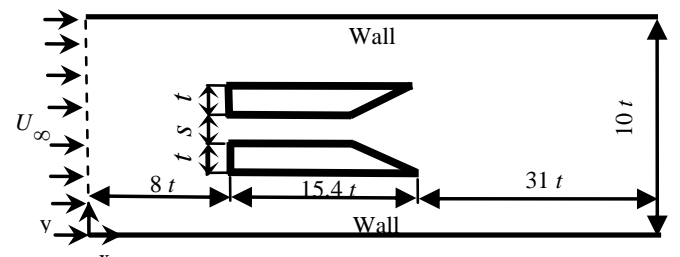

Fig. 1. Computational domain. 
The form of the steady scalar transport equation is:

$$
\frac{\partial}{\partial x}(\rho u \phi)+\frac{\partial}{\partial y}(\rho v \phi)+\frac{\partial}{\partial z}(\rho w \phi)=\frac{\partial}{\partial x}\left(\Gamma_{\phi} \frac{\partial \phi}{\partial x}\right)+\frac{\partial}{\partial y}\left(\Gamma_{\phi} \frac{\partial \phi}{\partial y}\right)+\frac{\partial}{\partial z}\left(\Gamma_{\phi} \frac{\partial \phi}{\partial z}\right)+S_{\phi}
$$

Where:

$\Gamma_{\phi}=$ diffusion coefficient

$S_{\phi}=$ source term

Table 1 shows the variables, coefficients, and source terms for the transport equations

\begin{tabular}{|l|l|l|l|}
\hline$\phi$ & Equation & $\Gamma_{\phi}$ & $S_{\phi}$ \\
\hline 1 & Mass conservation & 0 & 0 \\
\hline$u$ & x-momentum & $\mu_{e}$ & $\rho g_{y}-\partial p / \partial y$ \\
\hline$v$ & y-momentum & $\mu_{e}$ & $\rho g_{x}-\partial p / \partial x$ \\
\hline$k$ & Turbulent kinetic energy & $\mu_{t} / \sigma_{k}$ & $\mu_{t} \Phi-\rho \varepsilon$ \\
\hline$\varepsilon$ & Dissipation rate & $\mu_{t} / \sigma_{\varepsilon}$ & $C_{1} \mu_{t} \varepsilon / k-C_{2} \rho^{2} / k$ \\
\hline
\end{tabular}

where

$k \quad$ is the turbulent kinetic energy

$\varepsilon \quad$ is the turbulent kinetic energy dissipation rate

$\mu_{e} \quad$ is the effective viscosity

$\mu_{t} \quad$ is the turbulent viscosity

$\Phi \quad$ is the viscous dissipation

$\sigma_{k}, \sigma_{\varepsilon}$ are turbulence model coefficients (in $R N G k-\varepsilon$ turbulence model

$$
\sigma_{k}=\sigma_{\varepsilon}=0.72 \text { ) }
$$

The following boundary conditions are used:

- The inlet is placed some plates thickness upstream of the body, where $u=U_{\infty}$ and $v=0$ are prescribed

- No-slip condition is prescribed at the plate surface and duct walls, $u=v=0$

- At the outlet of the domain, atmospheric pressure is assumed

A two dimensional Reynolds-averaged incompressible Navier-Stokes code, Ansys/Flotran CFD was used to simulate the flow over the two-plate array. Ansys/Flotran is a CFD package contained in the ANSYS family of finite element. It solves the governing equations using a segregated velocity-pressure solution algorithm where the momentum equation is used to generate an expression for the velocity in terms of the pressure gradient.

A non-uniform grid was utilized. The grid was generated by Ansys software. The grid refinement was on the duct walls and along the plates surface. Different grids were used to check the grid-dependency of the solution. Solutions are compared with each other and with experimental data. It was found that a grid of 60152 nodes was enough to predict the flow. 


\section{EXPERIMENTAL SETUP AND TECHNIQUES}

The experiments were carried out in the test section of the water tunnel that is described in ref. [7] as shown in Fig. 2. The tunnel consists of a closed water circuit. The test section is $500 \mathrm{~mm}$ long and its cross-section is $25 \mathrm{~mm} \times 50 \mathrm{~mm}$. The four sides of the test section are made of Perspex for photographic and observational purposes. The maximum design speed in the test section is $10 \mathrm{~m} / \mathrm{s}$. The fresh tap water has been used as a working fluid. All tests have been conducted at room temperature.

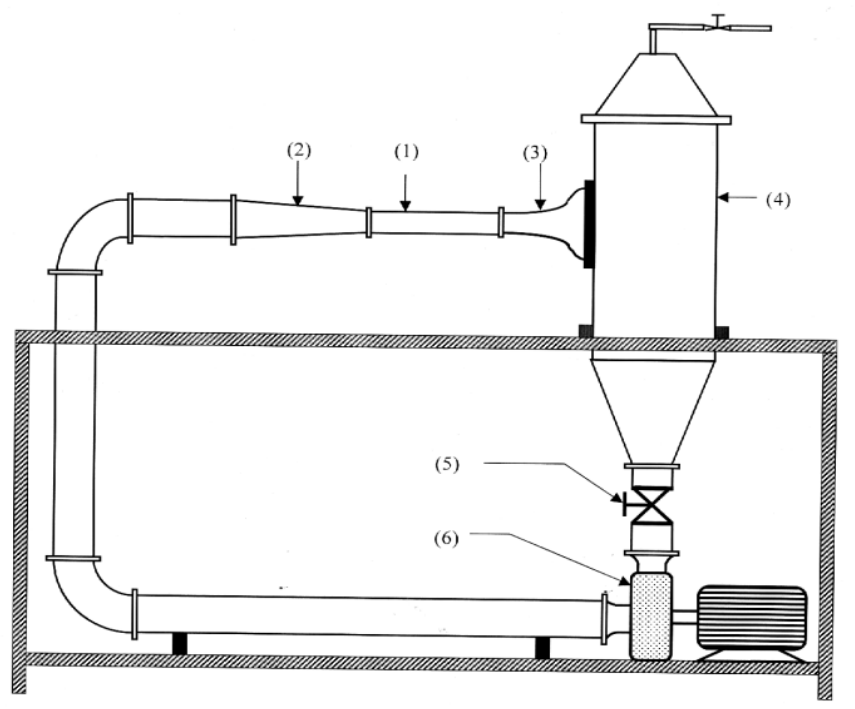

(1) Test section

(2) Diffuser

(3) Contraction section
(4) Resorber tank

(5) Valve

(6) Centrifugal pump

Fig. 2. Schematic diagram of the water tunnel

The test models used in the present experiments were two 2D blunt-faced flat plates. Each of the plates is $25 \mathrm{~mm}$ in span, $77 \mathrm{~mm}$ in long, $5 \mathrm{~mm}$ in thickness with a $20^{\circ}$ beveled trailing edge. The gap ratio was varied by changing the distance between the two plates, $s$. The tested gap ratios, $s / t$, were $0.5,1.0$ and 1.5. The effect of Reynolds number variation on the gap flow was examined by comparing the measured surface pressure values at two corresponding locations $(x / t=13.4$ and 14.8, where $x$ is the distance from the leading edge of the plates) on the beveled side of each plate for gap ratio $s / t=1.0$. The tested Reynolds number range was from $\mathrm{Re}_{t}=2.18 \times 10^{4}$ to $\mathrm{Re}_{t}=3.68 \times 10^{4}$ based on plate thickness, $t$. The static-pressure holes drilled in the beveled side were connected to mercury manometer boards by means of plastic tubes. The description and dimensions of the plates are illustrated in Fig. 3 for gap ratio $s / t=1.0$. The plates were made from Perspex and attached directly to the tunnel all to enhance the two-dimensionality of the flow along the span of the flat plates. Therefore, the 2D flow assumption along the plate centerline can be applied. The freestream water static pressure has been measured with a U-tube mercury manometer. 
The velocity in the test section has been measured by using the measured value of pressure difference across the contraction section with a mercury manometer. This has been achieved by calibrating the contraction section using a pitot tube.

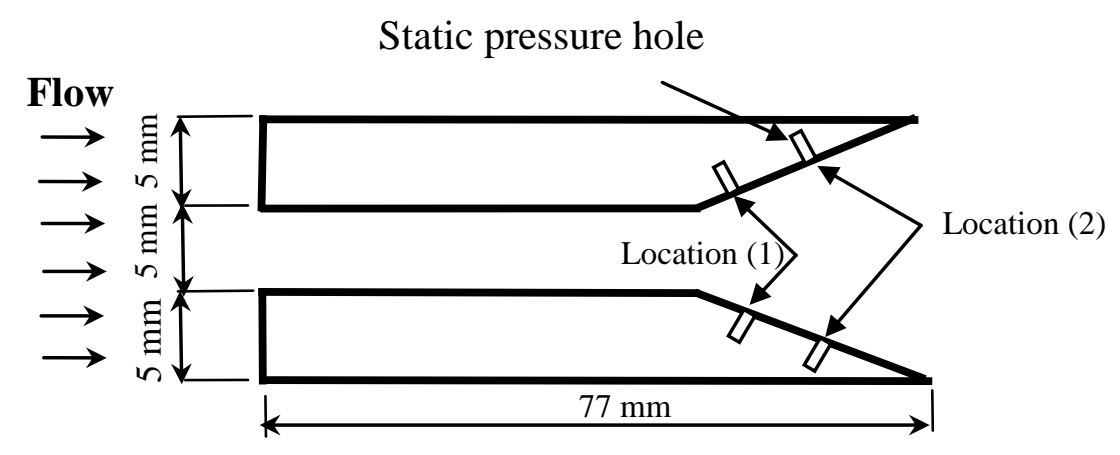

Fig. 3. Test model geometry

The wakes downstream the plates were visualized using the cavitation technique which was described in ref [7]. The flow visualization was made by establishing the tunnel pressure fixed, then increasing the speed until cavitation events occurred at the leading edge of the plates. The cavitation bubbles generated at the leading edge travel with the flow to the trailing edge. These bubbles visualize the flow in the near wake. The wake patterns were photographed using a digital camera. The photos were later computer processed and printed.

\section{RESULTS}

\section{Effect of gap size}

The numerical simulation and experimental results for $s / t=0.5$ are shown in Fig. 4 . The streamlines map and the photographs showed that the gap flow biases downward due to the vortex formation and shedding from the beveled edge of the upper plate. Also the pressure coefficient values at the beveled trailing edge of the upper plate are different from those at the beveled trailing edge of the lower plate as shown in Fig. 4b.

It can be demonstrated that the formation of the large vortex on the beveled edge surface of the upper plate leads to deflecting the flow toward the lower plate and consequently prevents the flow separation from the beveled edge of the lower plate. Therefore, the wake behind the plates shows an asymmetric development. Similar results for gap ratio $s / t=1.0$ were obtained by Mosallem [14]. For gap ratio $s / t=1.5$, Fig. 5 shows that the interference of the two plates is negligible and the wakes behind the two plates are independent of each other, where the gap flow appears to be non-biased state. This means that the gap size has a pronounced effect on the gap flow for gap ratios less than 1.5.

Figs 6 shows a comparison between the computed surface pressure distribution of each plate for gap ratio $s / t=1.5$ (symmetric wake). It can be observed that the surface pressure distribution is nearly identical for the two plates. In contrast, for gap ratio $s / t=1.0$ (asymmetric wake), Mosallem [14] found that there is a difference in 
the pressure distribution on the surface of each plate, particularly on the flat side and on the beveled trailing edge.

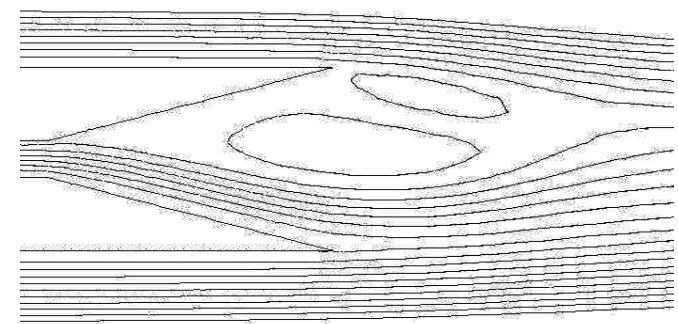

(a) Streamlines map

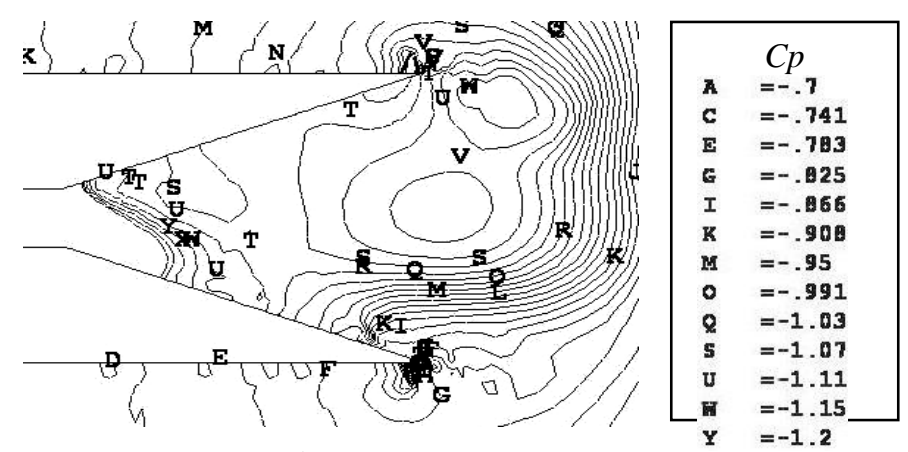

(b) Pressure contours

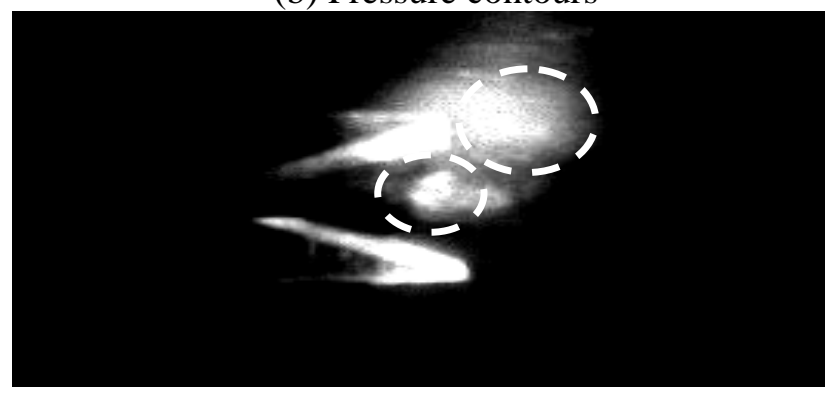

Fig. 4. Gap flow characteristics, $\left(s / t=0.5\right.$ and $\left.\mathrm{Re}_{t}=3.97 \times 10^{4}\right)$

\subsection{Effect of Reynolds Number}

As mentioned previously the effect of Reynolds number on the gap flow was examined by comparing the measured pressure values at two corresponding locations on the beveled side surface of each plate for gap ratio $s / t=1.0$. Figure 7 shows the results of measured pressure at the two locations as a function of Reynolds number. It can be observed that Reynolds number has some effect on the measured pressure values particularly at location (2), but the measured pressure displays distinct values on each plate at the two locations. This confirms that the wake at the trailing edges of the two plates is asymmetric. This means that Reynolds number has a weak effect on the gap flow characteristics within the tested range. 


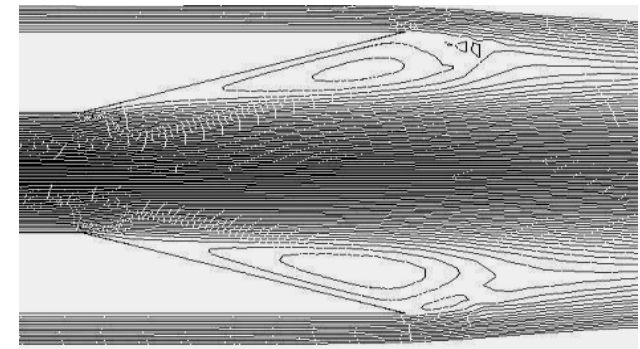

(a) Streamlines map

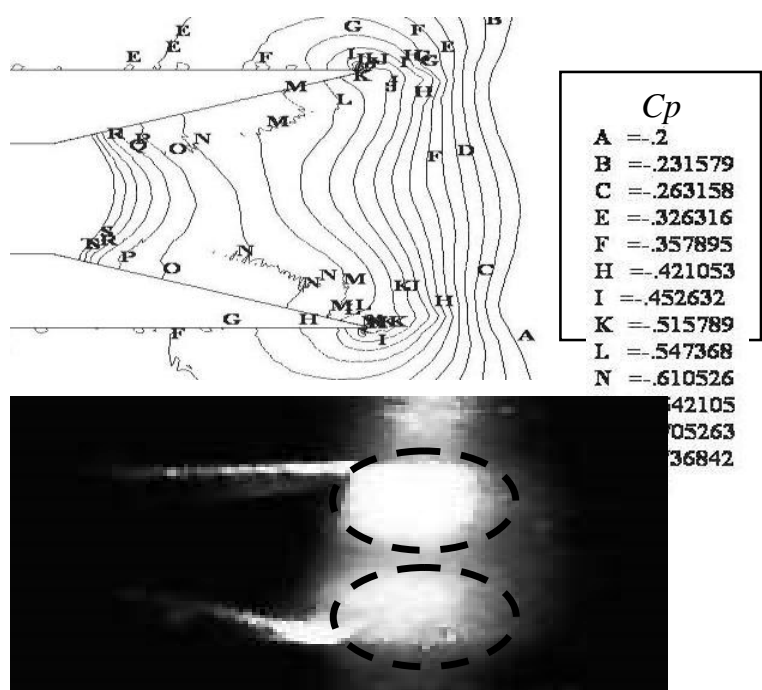

Fig. 5. Gap flow characteristics, $\left(s / t=1.5\right.$ and $\left.\operatorname{Re}_{t}=3.97 \times 10^{4}\right)$

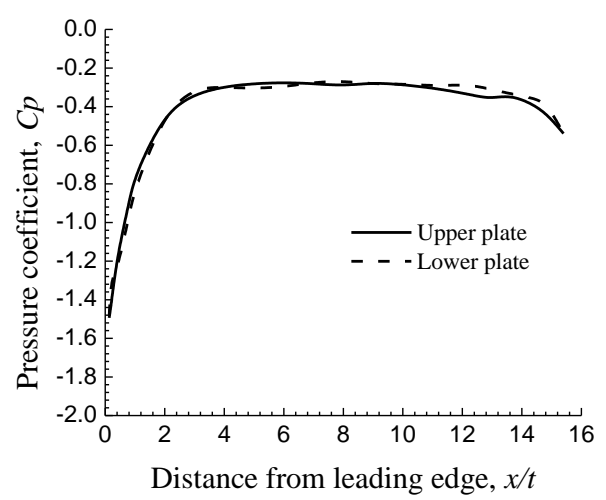

(a) Flat side

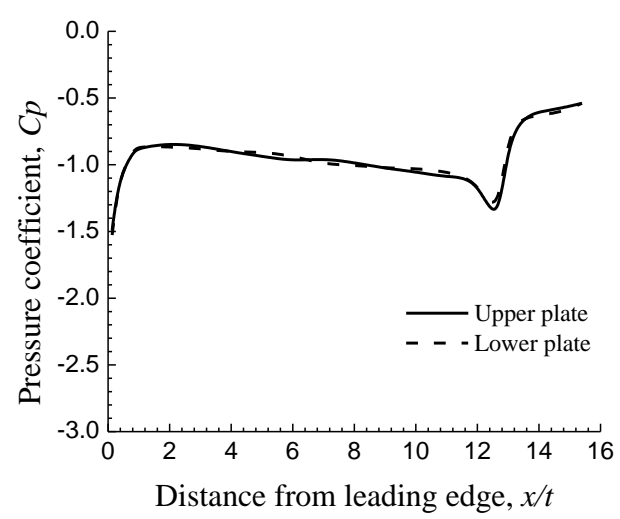

(b) Beveled side

Fig. 6. Computed pressure distribution on the two plates surface

$$
\left(s / t=1.5 \text { and } \operatorname{Re}_{t}=3.97 \times 10^{4}\right)
$$




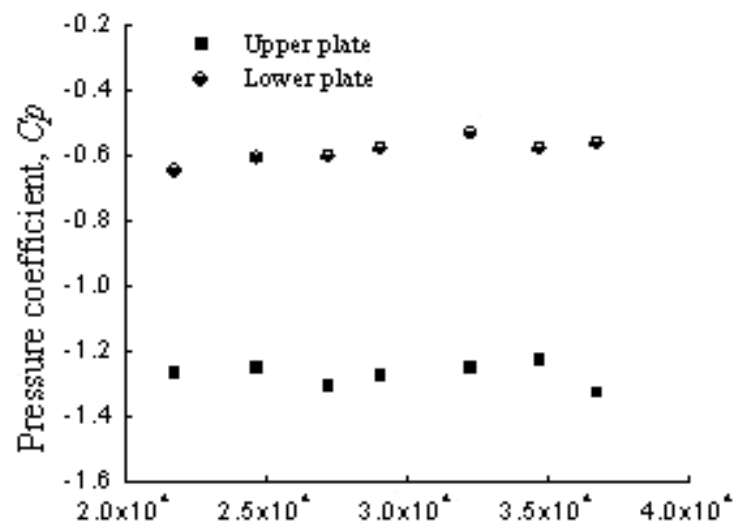

Reynolds number, $R e_{t}$

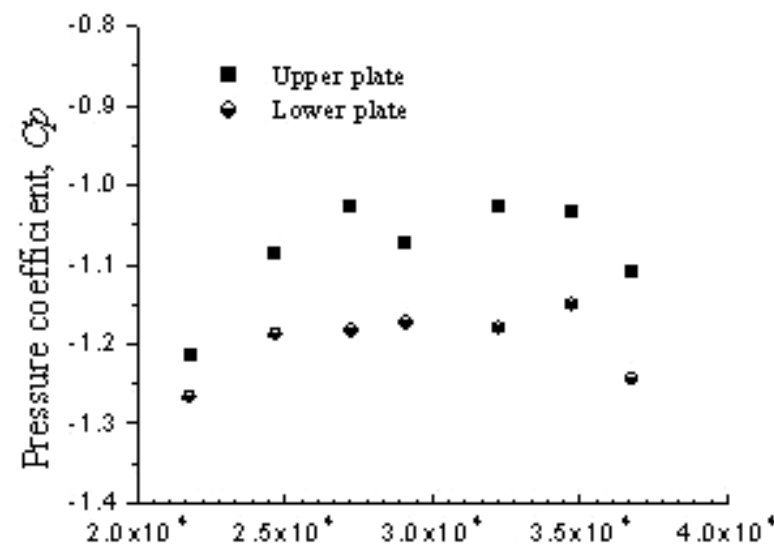

Reynolds number, $R \boldsymbol{e}_{t}$

Fig. 7. Effect of Reynolds number on the gap flow $(s / t=1.0)$

\section{CONCLUSIONS}

Numerical simulations and experimental visualization were carried out to investigate the effect of both gap size and Reynolds number variation on the flow between two plates having asymmetric beveled trailing edge placed side-by-side in a uniform stream. Two plates with gap ratios of $0.5,1.0$ and 1.5 and beveled trailing edge of angle $20^{\circ}$ have been tested. The results revealed that gap size variation has a pronounced effect on the gap flow for gap ratios less than 1.5, where the wake behind the two plates shows an asymmetric development for gap ratios 0.5 and 1.0. For gap ratio 1.5 , the interference of the two plates is negligible and the wakes behind the two plates are independent of each other, where the gap flow appears to be non-biased state. The results showed also that Reynolds number has a weak effect on the gap flow characteristics within the tested range. 


\section{REFERENCES}

[1] Bearman, P.W. and Wadcock, A.J. "The interaction between a pair of circular cylinders normal to a stream”, J. Fluid Mech., 61, 499-511, (1973).

[2] Zdravokovich, M.M. "Review of flow interference between two circular cylinders in various arrangements", Trans. ASME J.. Fluids Engng., 99, 618-633, (1977).

[3] Williamson, C.H.K. "Evolution of a single wake behind a pair of bluff bodies", $J$. Fluid Mech., 159, 1-18, (1985).

[4] Mosallem, M.M. "Investigation of wake characteristics downstream a pair of circular cylinders in a uniform flow", Bulletin of the Faculty of Engineering, Minia university, 22, 112, (2003)

[5] Kim, H.J. and Durbin, P.A. "Investigation of the flow between a pair of circular cylinders in the flopping regime", J. Fluid Mech., 1988, 196, 431-448.

[6] Kang, S. "Characteristics of flow over two circular cylinders in a side-by-side arrangement at low Reynolds numbers: Physics of Fluids, 2003, 15, 2486-2498.

[7] Kun, L., Dong-jun, M., De-jun, S. and. Xie-yuan, Y. "Wake patterns of flow past a pair of circular cylinders in side-by-side arrangements at low reynolds numbers", Journal of Hydrodynamics, Ser. B, 2007,19(6):690-697.

[8] Mosallem, M. M. "A study of wake characteristics downstream a pair of square bars in a uniform flow, $3{ }^{\text {rd }}$ Minia International Conference For Advanced Trends In Engineering, MICATE, 3-5 April, Faculty of Engineering, Minia university, Minia, Egypt (2005) 252-261.

[9] Agrawal, A., Djenidi, L. and Antonia, R. A. "Investigation of flow around a pair of side-by-side square cylinders using the lattice Boltzmann method", Computers \& Fluids 35 (2006) 1093-1107

[10] Hayashi, M., Sakurai, A., and Ohya, Y. Wake interference of a row of normal flat plates arranged side by side in a uniform flow. J. Fluid Mech., 1986, 164 p. 1-25.

[11] Miau, J. J., Wang, H. B., and Chou, J. H. Intermittent switching of gap flow downstream of two flat plates arranged side by side. J. Fluid struct., 1992, 6, p. 563-582.

[12] Miau, J. J., Wang, H. B., and Chou, J. H. Flopping phenomenon of flow behind two plates placed side-by-side normal to the flow direction. Fluid Dynamics Research, 1996, 17, p.311-328

[13] Guillaume, D.W. and LaRue, J.C. Investigation of the flopping regime of two-, three-, and four-plate arrays. Trans. ASME J. Fluids Engng., 2000, 122: 677-682.

[14] Mosallem, M. M. "Numerical and Experimental Study of Flow around Two Plates Having Asymmetric Beveled Trailing Edge". Journal of Hydrodynamics, Ser. B, Volume 20, Issue 5, October 2008, Pages 624-628 


\section{السريان خلف لوحين بينهما فجوة ولههما حافة خلفية مشطوفة \\ ملخص البحث}

فى هذا البحث نم دراسة تأثير كلا من المسافة البينية ورقم رينولز على خصائص السريان خلف لوحين أفقيين لهما حافة خلفية مشطوفة بزاوية 20 من جانب واحد وموضوعين عموديا على اتجاه السريان. وقد أجريت التجارب المعملية على اللوحين داخل نفق مائي وذلك بتغيير المسافة بين اللوحين

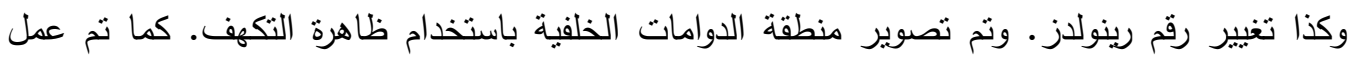
محاكاة عددية لمعرفة خصائص مجال السريان حول الألواح. وقد أظهرت النتائج العددية والصور

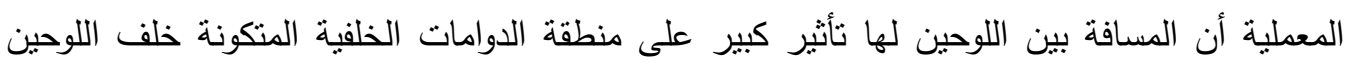

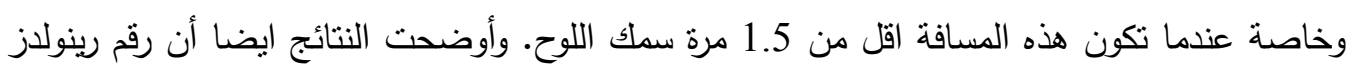
له تأثير ضعيف على خصائص هذه المنطقة بالرغم من نأثيره على قيم الضغط على سطح اللوحين. 